\section{Gategory}

Synthesis of

Materials and

Unnatural Products

\section{Key words}

fluorescent dyes

triazine
S. Rihn, P. RETAilleAu, A. DE NiCOLA, G. UlRiCh, R. ZIESSEL* (UNIVERSité De STRASBOURG AND LABORATOIRE DE CRYSTALLOCHIMIE, GIF-SUR-YVETTE, FRANCE) Synthetic Routes to Fluorescent Dyes Exhibiting Large Stokes Shifts J. Org. Chem. 2012, 77, 8851-8863.

\title{
Large Stokes Shift from Triazine-o-Phenol Dyes
}

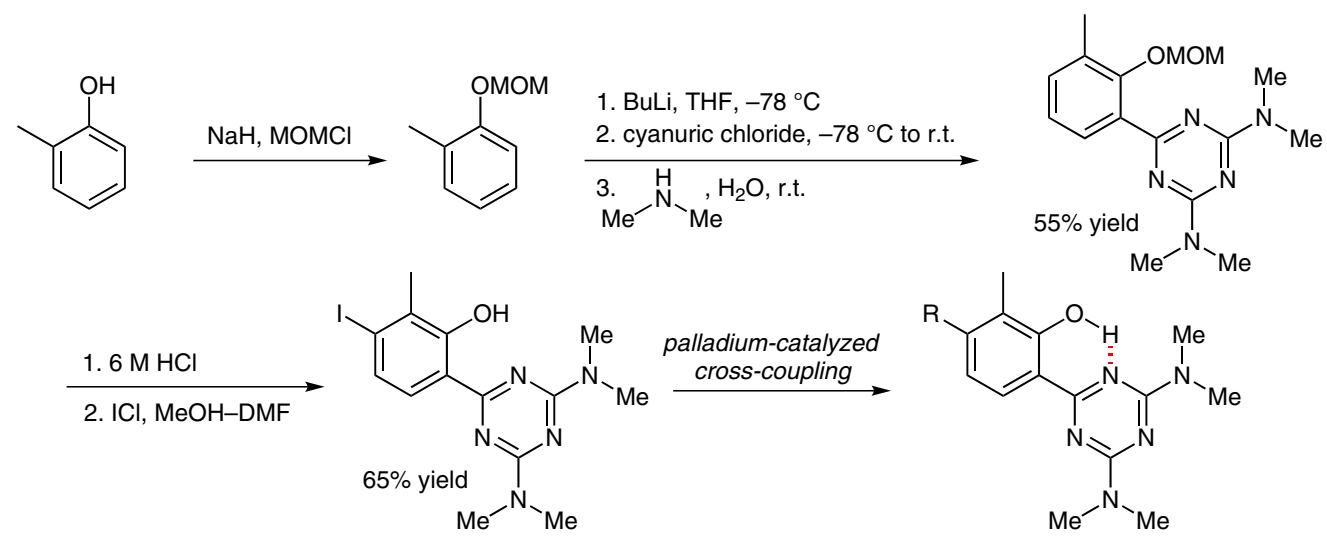

Selected chromophores:

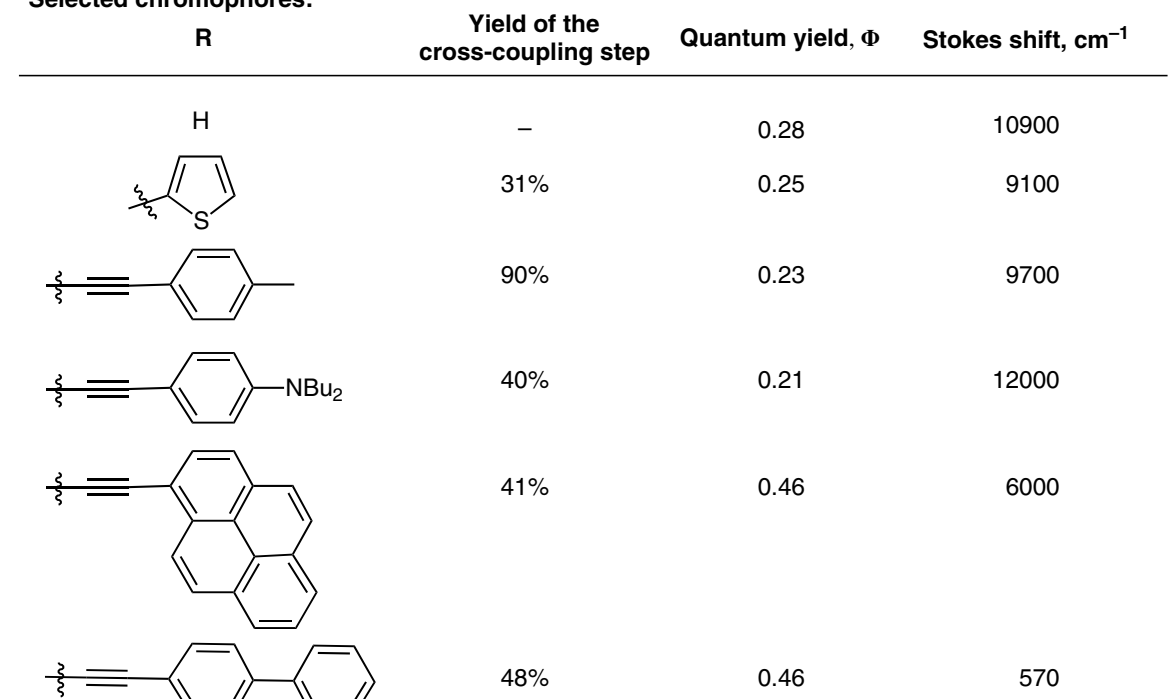

Significance: Fluorescent dyes exhibiting large Stokes shifts are of great interest for a multitude of applications. The authors report a straight-forward synthesis of a series of phenol-triazine dyes that exhibit hydrogen bonding in the ground state and undergo excited state intramolecular proton transfer (ESIPT), leading to the observation of large Stokes shifts.

sYNFACTS Contributors: Timothy M. Swager, Silvia V. Rocha Synfacts 2013,9(1), 0038 Published online: 17.12.2012 DOI: 10.1055/s-0032-1317886; Reg-No.: S13412SF
Comment: An exception to the observation of a large Stokes shift is the perylene-substituted dye; in this case, the perylene is responsible for the emission observed and the energy transfer occurs from the keto form to the perylene moiety. Also noteworthy is the large range of absorption and emission maxima exhibited by the family of dyes in this report. 